\title{
Leadership and the Creation of Corporate Social Responsibility: An Introduction to the Special Issue
}

\author{
Melanie De Ruiter ${ }^{1}$ Jaap Schaveling ${ }^{1} \cdot$ Joanne B. Ciulla ${ }^{2} \cdot$ André Nijhof $^{3}$
}

Received: 5 April 2018 / Accepted: 10 April 2018 / Published online: 28 April 2018

๑) Springer Science+Business Media B.V., part of Springer Nature 2018

In a recent interview, Apple's CEO Tim Cook said that when the government is less functional, it falls on businesses and other areas of society to "step up" (Sorkin 2017). His comment highlights what is perhaps the foundational question of Corporate Social Responsibility (CSR): Who is responsible for what? and when and how does a business decide to "step up"? Today, problems such as political divisions, negative reactions to globalization, immigration, Brexit, discrimination, and the emergence of populism and nationalism create environments that can challenge businesses to either "step up" or be complacent (Wettstein 2012). As Donaldson and Walsh (2015) explain, "business works both in and for society" (p. 182). If this is the case, it raises other key questions in CSR, such as how do businesses decide what their moral responsibilities are? And, in particular, what role do leaders play in CSR initiatives?

This special issue focuses on the last question and specifically addresses the role of leadership in the creation of CSR. It is not the first to address the linkage between leadership and CSR. In fact, leadership and CSR has been the topic of at least one previous special issue (i.e., Van Velsor 2009). Nevertheless, there is still a lot we do not know about the

Melanie De Ruiter

m.druiter@nyenrode.nl

Jaap Schaveling

jaapschaveling@me.com

Joanne B. Ciulla

jciulla@business.rutgers.edu

André Nijhof

a.nijhof@nyenrode.nl

1 Center for Leadership and Management Development, Nyenrode Business Universiteit, Breukelen, The Netherlands

2 Department of Management and Global Business, Rutgers Business School - Newark and New Brunswick, Newark, NJ, USA

3 Center for Entrepreneurship, Governance \& Stewardship, Nyenrode Business Universiteit, Breukelen, The Netherlands connection between leadership and the creation of CSR. Each of the articles in this special issue aims to contribute and broaden our understanding of this.

An important consideration in research on CSR is the level of analysis (Aguinis and Glavas 2012). In their conceptual paper on the role of leadership in CSR, Christensen et al. (2014) argue that a leader's characteristics and behaviors play an important part in the creation of CSR. A focus on individual traits (e.g., personality) and perceived behaviors and leadership styles describe the leader's role at the individual level of analysis. Yet, Aguinis and Glavas (2012) point out that research on the role of individuals (e.g., CEOs, top management team members) in the context of CSR can also be considered at the organizational level of analysis. They explain that studies incorporating macro theories conceptualize the role of individuals at the organizational level and should, therefore, be treated at that level of analysis. Since most research on CSR has been conducted from the institutional and organizational level of analysis, the field would benefit from more studies done from the individuallevel perspective (Aguinis and Glavas 2012; Morgeson et al. 2013). In this special issue, both perspectives are represented.

Christensen et al. (2014) point to the importance of leadership styles for the creation of CSR. Although a number of studies have examined the relationship between leadership styles and CSR, the focus has often been on transformational leadership. According to Wu et al. (2015), transformational leadership fails to adequately consider a leader's ethics. Moreover, Robertson and Barling (2013) argue that the general conceptualization of transformational leadership does not take into account how transformational leadership behaviors are expressed in relation to a specific outcome. Furthermore, Christensen et al. (2014) point to the importance of leadership models that provide a clear link between leader behaviors and the creation of CSR. Some authors have called for more research on leadership styles, such as ethical leadership (e.g., Christensen et al. 2014; Wu et al. 2015) and 
responsible and servant leadership (Christensen et al. 2014). A few articles included in this special issue answer these calls by focusing on ethical leadership and environmentally specific transformational leadership.

Morgeson et al. (2013) distinguish between objective and subjective measures of CSR practices. Objective measures are often based on evaluations of the company's CSR practices by analysts external to the organization, while subjective measures frequently rely on internal employee beliefs about the organization's CSR practices (Morgeson et al. 2013). Both types of measures are represented in this special issue. However, some articles in this special issue also frame CSR at the employee level. For example, Robertson examines pro-environmental behavior in the workplace. Thus, some studies move beyond organizational CSR practices, to explore the role of leadership in fostering CSR behaviors at the employee level. This fits with the approach taken by Gond et al. (2017), who indicate that in research on individual-level antecedents of CSR engagement, a broader conceptualization that also includes employee behaviors can be used.

The first cluster of articles focuses on the developmental processes involved in becoming CSR leaders. In "A Falling of the Veils: Turning Points and Momentous Turning Points in Leadership and the Creation of CSR", Hemingway and Starkey (2017) use interviews to study how turning points in an individual's life affect his or her inclination to be a CSR leader. They discover that (momentous) turning points (i.e., existential workplace experience, enlightened educational experience, religious epiphany, and critical family illness/bereavement) play a key role in this process because they cause individuals to move from instrumental drivers (i.e., self-interested concerns), through affective states, to moral drivers for CSR (i.e., reflexivity and self-transcendent values).

In the next article, "Unraveling the Competence Development of Corporate Social Responsibility Leaders: The Importance of Peer Learning, Learning Goal Orientation, and Learning Climate", Osagie et al. (2017) conduct a study among CSR professionals to understand how they develop the competencies needed to be effective. They found that these professionals often develop competencies from informal learning activities with and from others outside the company. Moreover, the authors discovered that developing a learning goal orientation strongly affected the ability of leaders to initiate and facilitate CSR activities. This orientation is important because often the CSR challenges that leaders face fall outside of traditional approaches to business.

The second cluster of articles focuses on the connection between perceptions of leadership and organizations, employee CSR practices, or both. In their article, "How Perceived Corporate Social Responsibility Affects Employee Cynicism”, Serrano-Archimi, Reynaud, Yasin, and Bhatti tackle the question of how employee perceptions of their organization's CSR practices reduce employee cynicism toward the organization, and they specifically examine the mediating role of trust in this relationship. The authors explain that trust in company leaders mediates the relationship between four types of perceived organizational CSR practices (economic, legal, ethical, and discretionary) and employees' cynicism. These perceived CSR practices positively affect perceptions of trust, which in turn reduces employee cynicism towards the organization.

The study by De Roeck and Farooq (2017) has a comparable outcome. Their paper "Corporate Social Responsibility and Ethical Leadership: Investigating Their Interactive Effects on Employees' Socially Responsible Behaviors", aims to explain employees' socially responsible behaviors. They find that organizational identification is a significant mediator between perceptions of organizational CSR and socially responsible behaviors of employees. Although trust and organizational identification are concepts from different theoretical views, it is striking to see the overlap in arguments for why both trust and organizational identification can mediate the relationship between organization CSR and employee behavior, be it employee cynicism or employee CSR (socially responsible behaviors). De Roeck and Farooq also find that ethical leadership has a moderating effect on the relationship between perceptions of CSR, organizational identification, and socially responsible behavior.

Pasricha et al. (2017) also investigate the role of ethical leadership in their article "Ethical Leadership, Organic Organizational Cultures and Corporate Social Responsibility: An Empirical Study in Social Enterprises". However, in their study, they theorize that ethical leadership will have a direct rather than a moderating effect on CSR. This different approach is due to their focus on a subset of business, social enterprises, where ethical leadership is more prevalent than in conventional businesses. Their research also shows an indirect effect of ethical leadership on CSR. This indirect relationship involves the mediating role of nurturing clan and adhocracy cultures, which in turn influence CSR.

In the article, "The Nature, Measurement and Nomological Network of Environmentally Specific Transformational Leadership", Robertson (2017) also focuses on the direct relationship between leadership style and CSR. However, she focuses on environmentally specific transformational leadership and CSR at the employee level. She uses four studies to develop and validate a questionnaire for the measurement of environmentally specific transformational leadership. She shows that environmentally specific transformational leadership explains incremental variances in employees' workplace environmental behaviors above the general notion of transformational leadership. Her research thus shows the importance of measuring environmentally specific transformational leadership in the context of CSR. 
Her questionnaire offers researchers a tool for measuring this.

The last cluster of articles in this special issue frame the role of leadership in the creation of CSR from a board perspective. In the paper "Unpacking Functional Experience Complementarities in Senior Leaders' Influences on CSR Strategy: A CEO-Top Management Team Approach", Reimer et al. (2017) use upper echelons theory to explain the expected relationship between functional complementarities at the CEO-top management team (TMT) interface and CSR strategies. Macauley et al. (2017) in their paper on "Alliance Network Centrality, Board Composition, and Corporate Social Performance", draws on stakeholder theory to help explain the relationship between board composition and corporate social performance. It also employs a resourcebased and an alliance learning perspective to help explain how alliance network centrality affects the corporate social performance of an organization. Both studies use an objective measure of CSR at the organizational level of analysis. While Reimer et al. include different dimensions to examine a multifaceted construct of CSR, Macauley et al. used an aggregate measure to examine corporate social performance.

The findings from Reimer et al.'s study demonstrate the relevance of focusing on multiple facets of CSR. Reimer et al. show that when CEOs with the greatest experience with output functions are complemented by a TMT with few members with output experience, the dimensions community, product, and diversity are affected. Yet, CSR employee relations are most affected when CEOs with predominant experience in output functions are complemented with TMT members who also predominantly have experience with output functions. The authors did not find a significant effect on CSR environment.

While Reimer et al. stress the importance of focusing on multiple facets of CSR, Macauley et al. argue that by examining the influence of female directorship and network centrality, the literature benefits from a broader conceptualization of corporate social performance. The authors point out that these antecedents have been theorized or examined in relation to narrow definitions of social performance. Hence, by focusing on a broader conceptualization, the authors are able to show the implications of female directorship and network centrality. The results of their study show that when there are more female directors on a board, the corporate social performance is higher than when there are fewer female directors on a board. Furthermore, when outside directors are included on a board, the positive relationship between female directorship and corporate social performance is strengthened. Moreover, their results show that network centrality positively affects a firm's social performance.

The papers included in this special issue provide important insights into the role of leadership in the creation of
CSR. A curious thing about leadership in organizations (and leadership in general) is that we do not pay much attention to it until a leader or a group does something really bad or really good. It is at these times we realize that for better or for worse, leaders matter. In organizations, people work as parts of groups and it often takes one or more people to move that group to embrace certain values, go in a new direction, or do things in a different way. Such people are leaders either because of their job titles, or their ideas, and/ or their ability to influence others. Without them, CSR initiatives are unlikely or perhaps impossible. The challenge for leaders who want to create a business case for CSR is not unlike the pressing moral challenge that leaders face in politics and other walks of life. In society and in organizations, they find a fertile ground for fear, anger, greed, distrust, and indifference. Yet, the moral challenge of CSR leaders, and other leaders, is to move people and organizations to listen to their better angels and do what is right for both their organizations and society. The value of the articles in this special issue is that they offer us a way to understand how leaders do this in the creation of CSR.

Acknowledgements We want to thank all of the people who submitted papers to this issue and the thoughtful reviewers who took the time to offer their helpful comments on how to improve them. We had a number of good submissions but alas, we could not take them all. We would also like to thank our editor Michelle Greenwood for her infinite patience and support of this project.

\section{Compliance with Ethical Standards}

Conflict of interest All authors declare that they have no conflict of interest.

Research Involving Human and Animal Participants This article does not contain any studies with human participants or animals performed by any of the authors.

\section{References}

Aguinis, H., \& Glavas, A. (2012). What we know and don't know about corporate social responsibility: A review and research agenda. Journal of Management, 38, 932-968.

Christensen, L. J., Mackey, A., \& Whetten, D. (2014). Taking responsibility for corporate social responsibility: The role of leaders in creating, implementing, sustaining, or avoiding socially responsible firm behaviors. The Academy of management Perspectives, 28(2), 164-178.

De Roeck, K., \& Farooq, O. (2017). Corporate social responsibility and ethical leadership: Investigating their interactive effect on employees' socially responsible behaviors. Journal of Business Ethics. https://doi.org/10.1007/s10551-017-3656-6.

Donaldson, T., \& Walsh, J. P. (2015). Toward a theory of business. Research in Organizational Behavior, 35, 181-207. https://doi. org/10.1016/j.riob.2015.10.002.

Gond, J. P., El Akremi, A., Swaen, V., \& Babu, N. (2017). The psychological microfoundations of corporate social responsibility: 
A person-centric systematic review. Journal of Organizational Behavior, 38(2), 225-246.

Hemingway, C. A., \& Starkey, K. (2017). A falling of the veils: Turning points and momentous turning points in leadership and the creation of CSR. Journal of Business Ethics. https://doi.org/10.1007/ s10551-017-3659-3.

Macaulay, C. D., Richard, O. C., Peng, M. W., \& Hassenhutl, M. (2017). Alliance network centrality, board composition, and corporate social performance. Journal of Business Ethics. https://doi. org/10.1007/s10551-017-3566-7.

Morgeson, F. P., Aguinis, H., Waldman, D. A., \& Siegel, D. S. (2013). Extending corporate social responsibility research to the human resource management and organizational behaviour domains: A look to the future. Personnel Psychology, 66, 805-824.

Osagie, E. R., Wesselink, R., Runhaar, P., \& Mulder, M. (2017). Unraveling the competence development of corporate social responsibility leaders: The importance of peer learning, learning goal orientation, and learning climate. Journal of Business Ethics. https://doi.org/10.1007/s10551-017-3638-8.

Pasricha, P., Singh, B., \& Verma, P. (2017). Ethical leadership, organic organizational cultures and corporate social responsibility: An empirical study in social enterprises. Journal of Business Ethics. https://doi.org/10.1007/s10551-017-3568-5.

Reimer, M., Van Doorn, S., \& Heyden, M. L. (2017). Unpacking functional experience complementarities in senior leaders' influences on CSR strategy: A CEO-Top management team approach. Journal of Business Ethics. https://doi.org/10.1007/ s10551-017-3657-5.

Robertson, J. L. (2017). The Nature, measurement and nomological network of environmentally specific transformational leadership. Journal of Business Ethics. https://doi.org/10.1007/s1055 1-017-3569-4.

Robertson, J. L., \& Barling, J. (2013). Greening organizations through leaders' influence on employees' pro-environmental behaviors. Journal of Organizational Behavior, 34(2), 176-194.

Sorkin, A. (2017) Apple's Tim Cook Barnstorms for 'Moral Responsibility' Deal Book, The New York Times August 28, 2017, https:// www.nytimes.com/2017/08/28/business/dealbook/tim-cook-apple -moral-responsibility.html Accessed 3 Nov 2018.

Van Velsor, E. (2009). Introduction: Leadership and corporate social responsibility. Corporate Governance: The International Journal of Business in Society, 9(1), 3-6.

Wettstein, F. (2012). Silence as complicity: Elements of a corporate duty to speak out against the violation of human rights. Business Ethics Quarterly, 22(1), 37-61.

Wu, L. Z., Kwan, H. K., Yim, F. H. K., Chiu, R. K., \& He, X. (2015). CEO ethical leadership and corporate social responsibility: A moderated mediation model. Journal of Business Ethics, 130(4), 819-831. 